\title{
Design and Implementation of Passive Dynamic Vibration Absorber for Vibration control of rotating mass unbalanced Air Blower
}

DOI : 10.36909/jer.ICIPPSD.15523

\author{
A. J. Sheth* and U. A. Patel** \\ *Gujarat Technological University, Ahmedabad, Gujarat, India \\ **L D College of Engineering, Ahmedabad, Gujarat, India \\ *Email: shethanant1981@gmail.com; Corresponding Author
}

\begin{abstract}
Frequently it is found in the industry that unbalances of the rotating components generate vibration due to centrifugal force. Here an attempt has been made to reduce vibrations caused by unbalance in the impeller of the Air Blower. The Dynamic Vibration Absorber (DVA) device is designed in such a way that optimal tuning damping factor and mass ratio were found as same as that obtained by using higher order of perturbation method. The designed DVA brings Vrms values within the limit set by ISO 10816-3 for Unlimited Long-Term Operation Allowable. More than 50\% appreciable vibration reduction was measured in radial horizontal and vertical direction both at the motor drive and non-drive end.
\end{abstract}

Keywords: - Air Blower; Dynamic Vibration Absorber; Optimal damping factor; Rotating mass unbalance; Rubber strip damper.

\section{INTRODUCTION}

For controlling vibrations induced by various types of excitations optimal parameters for DVA were determined analytically. For the practical implementation of DVA, these derivations are considered as the reference for the tuning process over a small or large frequency range. The efforts for the determination of the optimal parameters for vibration control of Undamped primary structure was carried out by attaching Undamped DVA (Watts, P., 1883) The natural frequency ratio, an optimal tuning parameter equation was determined (Frahm, H., 1909). By using the "Fixed-point theory" where all frequency response curves pass through two fixed points irrespective of damping (Ormond Royd, J. \& Den Hartog, J.P., 1928). For a broad range of vibration control, damped DVA needs to be used. The optimal damping factor equation was also determined (Brock, J. E., 1946). The single DOF DVA extended to multiple DOF systems (Warburton, G.B.,1981). The MDOF DVA is naturally 
performed more effectively compared to SDOF DVA but the system becomes bulky. The concept of DVA for lumped mass systems using piezoelectric patches extended for the vibration control of beam (Ioi, T.\& Ikeda, K., 1978) the author proposed an analytical solution for the Ho optimization in the form of power series in powers of the damping of the primary system. The solution is truncated by a second-order approximation. The H2 optimization problem of the dynamic vibration absorber ends up with a problem for solving a quartic equation. The exact solution is given by a set of expressions (Asami,T., Osamu, N. \& Amr, M.B.,2002). The optimum parameters using the $\mathrm{H} 2$ optimization method for the DVA of non-traditional form are derived to minimize the total vibration energy. The variant DVA with frequency ratio 2 and 3 The mass ratio of the DVA in practice is about 10-30\% (Cheung,Y.L.\& Wong,W.O.,2002). The optimal damping factor is obtained by doing little modification in Broke's approach by using the perturbation method. In a perturbation method here the higher order is neglected and only a lower order is considered. The main goal was to determine optimal parameters of Geometrically Modified DVA for the undamped primary system (Cheung,Y.L.\& Wong,W.O.,2002). DVA optimum parameters attached to a viscously damped single degree of freedom main system are derived for various combinations of excitation and response parameters. The main system was modeled as a Gaussian white-noise random excitation. After that, a curve fitting technique is applied to determine the optimal parameters. These solutions can be readily used for practical applications (Bakrez, S.V. \& Jangid, R.S.,2007). The rotating unbalance generated inertial forcing depends on the fourth power of forcing frequency and it was reflected in the optimal tuning parameters that differ from classical values obtained for constant harmonic forcing. Analytical results demonstrate that frequency and damping ratios, as a function of the mass ratio, should be higher than classical optimal parameters. For practical applications, a properly tuned DVA appreciate a reduction in the steady-state response of about $20 \%$ concerning the response achieved with a classically tuned damper (Argentini, T.,2015). The optimal damping factor was determined by considering higher orders in a perturbation method. The effect of this solution has been compared numerically with solutions proposed by $\mathrm{H} \infty$ method, the Equivalent Linearization method, solution proposed by Ioi \& Ikeda. The comparison states that the required DVA damping factor percentage has been reduced by $85 \%$ to $75 \%$ for the mass ratio range 0.05 to 0.125 respectively (Sheth, A.J. \& Patel, U.A.,2020). Rather than going for analytical optimization based on the numerical results the tuning of TVA was done. The setup consists of vibrating mass discs supported by steel springs. Both are located, together with damping oil, inside a cylindrical steel frame. All the damper parameters, mass, stiffness, and damping 
can be separately adjusted. The damping coefficient is changed by altering the oil flow inside the damper (Tienhaara, H. \& Heikki, M.,2008). To reduce bearing vibration due to rotating unbalance self-balancing technique by using GA implemented (Taplak, H. 2012). The Periodic Vibration Absorber (PVA) has two cantilever beams interconnected with an intermediate discrete spring. Here it is noted that harmonics (mainly the first three) contain about $90 \%$ of the overall excitation the design of PVA is done by keeping these lower frequencies (Huang, S.C. \& Lin, K.A.,2014). Dual mass DVA for controlling rotating mass unbalance setup is designed. Manually mass is adjusted on the dual mass DVA (Abdullah, O., 2015). The concept of distance ratio is used to attenuate vibration due to rotating Unbalance mass. The rise of the distance ratio will cause a decrease in the percentage of vibration reduction in translational motion on the contrary rise in the percentage of vibration reduction in rotational motion (Aida, A. \& Daman, A. 2016). The cantilever beam with rotating mass unbalance and simply supported beam with cantilever movables mass DVA was numerically tested with ANSYS and then experimentally using OROS 34 vibration analyzer (Ghodge, V., 2018). For a case of flexible multi bearing unbalance rotor system it was found that by wrong prediction of damping coefficient the critical speed was found to be more than experimental values (Falah, A. H.\& Khorshid, E.A., 2014). Adaptive control rough cutting strategy was adapted where speed feed and depth of cut were varing as per the feedback available. When vibration increases all the cutting parameter were adjusted (Alaskari, A.M. \& Oraby, S.E.2018). A new waveform acceleration command shaper numerical technique was derived, and this numerical model was applied on the crane. With this numerical technique the displacement, velocity and acceleration were found smoother compared to the conventional step input (Alhazza, K.A. \& Masoud, Z.N.,2013). The role of damping has been studied in the case of deformable material and flat surface. The experimental result shows at low speed the normalized force mainly depends on the damping (Christoforou,A.P. \& Yigit, A.S. 2016). Inclusion of the Psychoacoustics as one of the important parameters of car door design inspires one to include the same parameter in the design where vibration and acoustics were concerned (Wonjoon, K.; Donggun, P.; Yong, M. K.; Taebeum, R. \& Myung, H. Y. 2018).

\section{METHODOLOGY}

A setup has been made by using a blower that runs at $2550 \mathrm{rpm}$ with the help of a motor of $0.5 \mathrm{HP}$ as an external drive. The blower rotor mass is $1.168 \mathrm{Kg}$. with one blade mass 0.015 Kg. There are 36 blades. The blower rotor rotates in a casing mounted 6300 pre-lubed with grease and sealed precision single-row ball bearing. For the placement of DVA a little bit of 
modification is done. The motor drive-end shaft is extended for a length of $10 \mathrm{~mm}$. For creating unbalance one of the blades is broken. Utmost care is taken for the proper foundation of the motor and the blower.

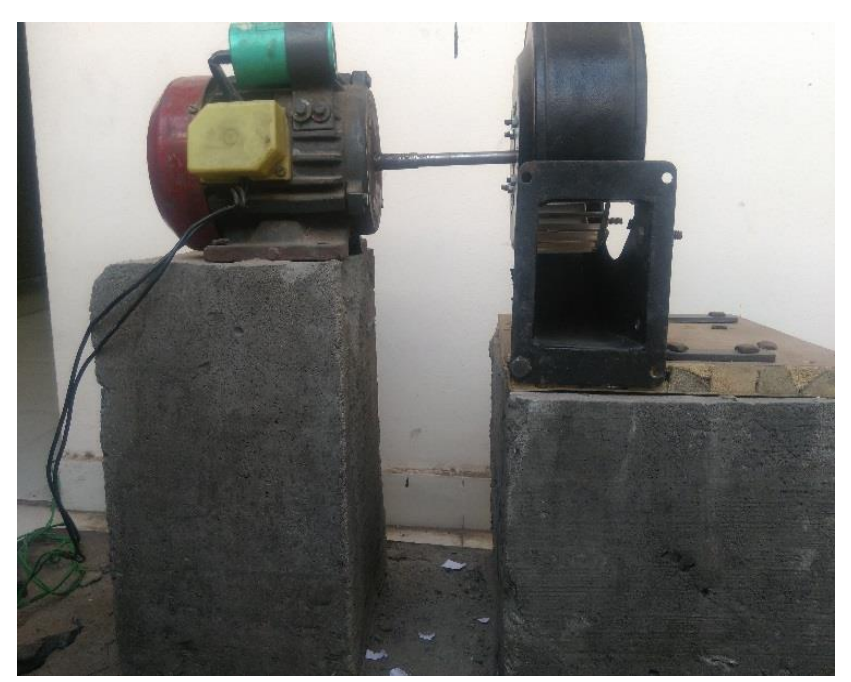

Figure 1 Experimental setup.

The vibration readings were taken at the motor drive end (MDE) and the motor non-drive end (MNDE).

The vibration spectrum in radial- $\mathrm{H} \& \mathrm{~V}$, Axial directions were taken.

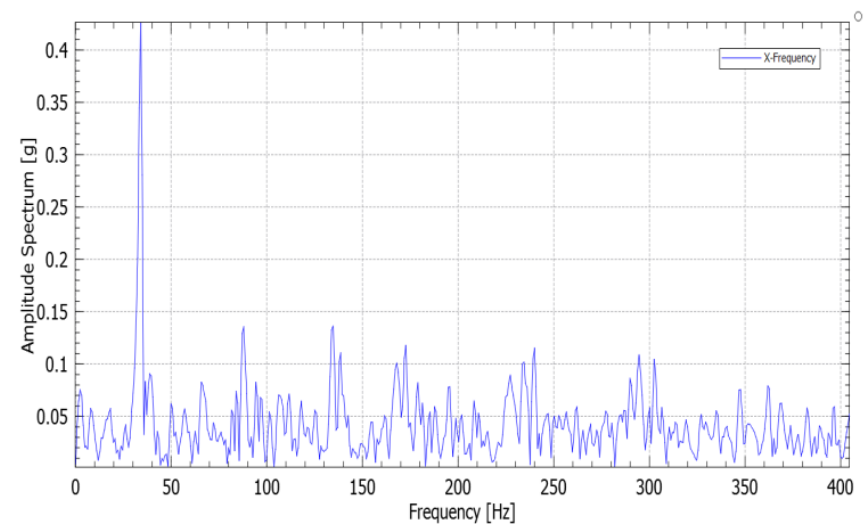

Figure 2 Vibration spectrum at the MDE (Radial-vertical Direction) before attaching DVA.

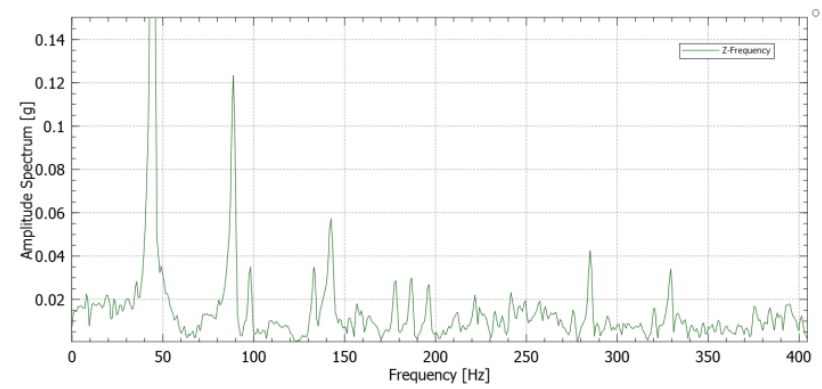


Figure 3 Vibration spectrum at the MDE (Radial-H Direction) before attaching DVA.

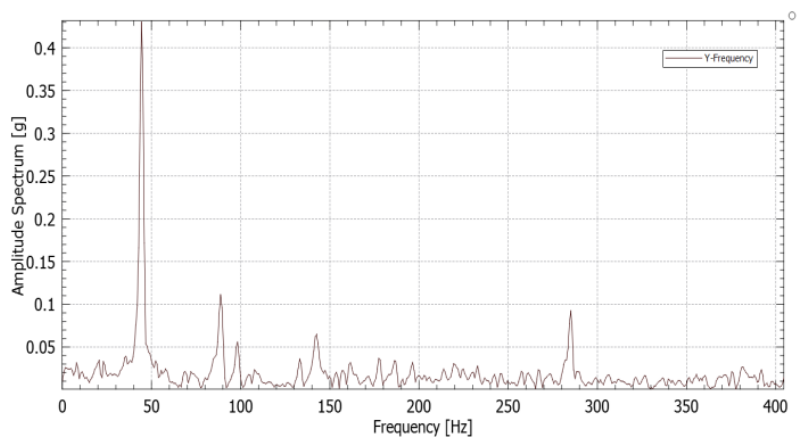

Figure 4 Vibration spectrum at the MDE (Axial Direction) before attaching DVA.

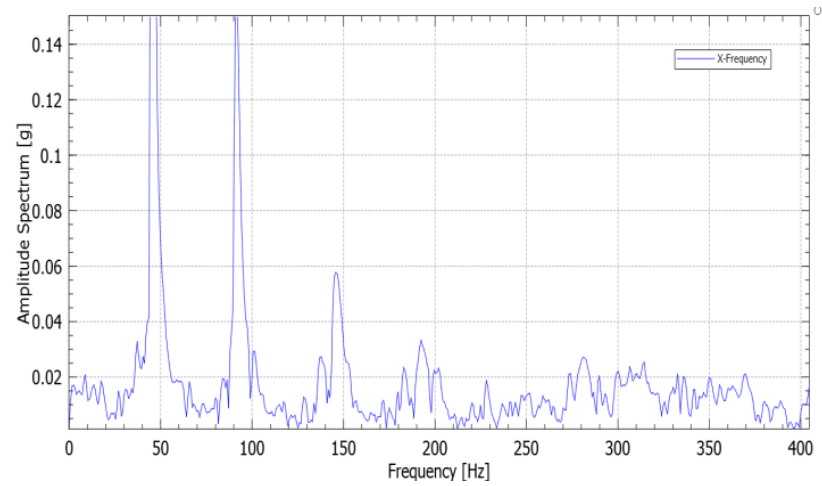

Figure 5 Vibration spectrum at the MNDE (Radial-vertical Direction) before attaching DVA.

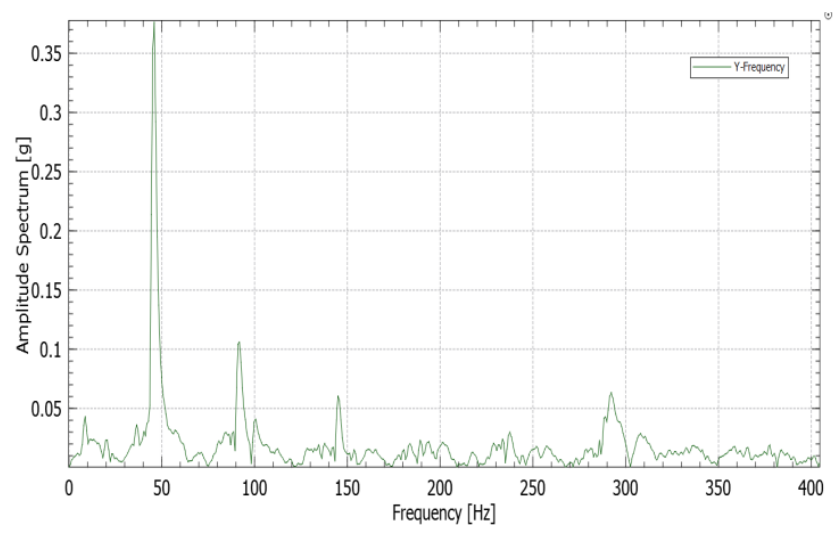

Figure 6 Vibration spectrum at the motor non-drive end (Radial-H Direction) before attaching DVA.

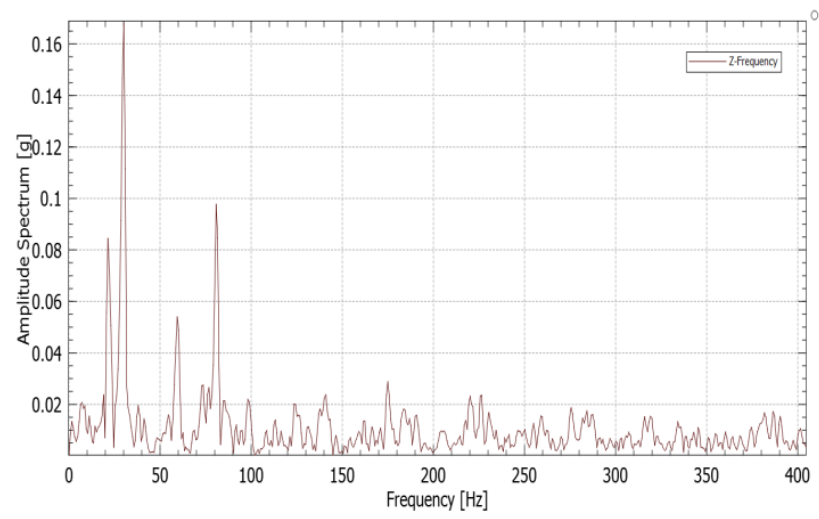

Figure 7 Vibration spectrum at the motor drive end (Axial Direction) before attaching DVA. 


\section{DESIGN OF DVA}

Challenges in designing DVA.

1. Damping material selection.

2. To incorporate axial clearance which will take care of axial vibrations.

3. Determination of DVA mass.

The determined steady state amplitude is $X=4.8 \mathrm{~mm}$.

Frequency ratio $\frac{\omega}{\omega_{n}}=1.1$.

$$
\frac{X}{\left(\frac{m_{0} e}{m}\right)}=\frac{\left(\frac{\omega}{\omega_{n}}\right)^{2}}{\sqrt{\left(1-\left(\frac{\omega}{\omega_{n}}\right)^{2}\right)^{2}+\left(2 \xi \frac{\omega}{\omega_{n}}\right)^{2}}}
$$

$\mathrm{e}=$ eccentricity of blower rotor $=75 \mathrm{~mm}$.

$\xi=$ Damping factor

$$
\begin{gathered}
\frac{4.8 * 10^{-3}}{\left(\frac{0.015 * 0.075}{1.168}\right)}=\frac{(1.1)^{2}}{\sqrt{\left(1-(1.1)^{2}\right)^{2}+(2 \xi(1.1))^{2}}} \\
\xi=0.055 .
\end{gathered}
$$

The DVA is designed as an eccentric ring with an inner race of a soft rubber sheet having a damping factor 0.07 (Lijesh, K.P. \& Hirani, H. 2014). Applying the Magnification Factor equation for determining DVA damping factor we get 0.05 . Thus, we can use soft rubber as a damping agent for the DVA.

Mass ratio $(\mu)=$ DVA mass/ Rotor mass

$$
\begin{aligned}
& =210 / 1168 \\
& =0.179 .
\end{aligned}
$$

The following is the setup where DVA has been attached to the blower for its vibration control. The DVA presented here is called "Dual strip damped DVA". The two metallic dual grounded flats will help in damping the vibrations as in Figure. 8 we can see the rubber strips avoid the metal-to-metal contact and have taken care of vibrations transmitted through rotating mass unbalance. 


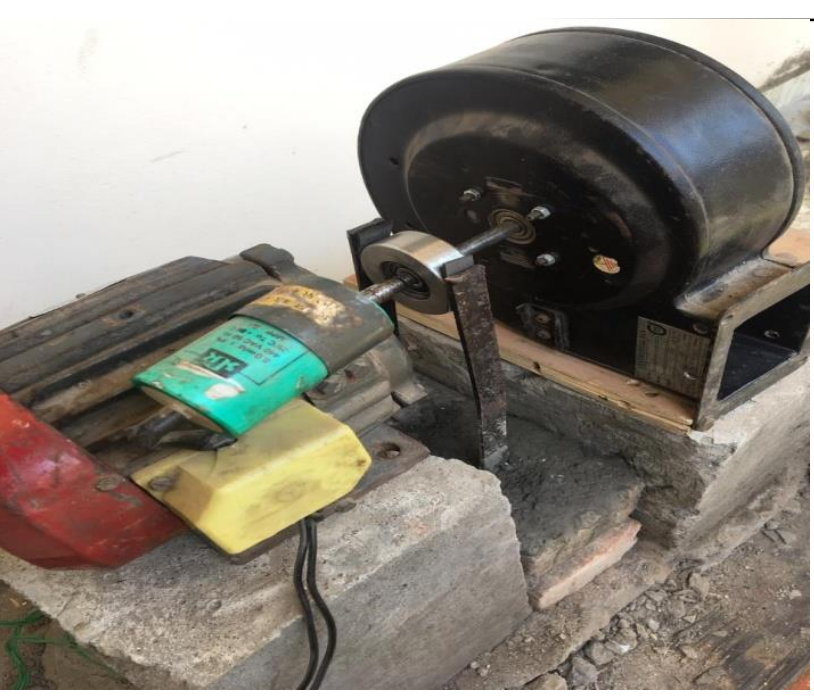

Figure 8 Experimental setup for Air Blower with DVA.

\section{RESULTS}

The FFT analyzer is attached to the Motor Drive end as well as Non drive end.

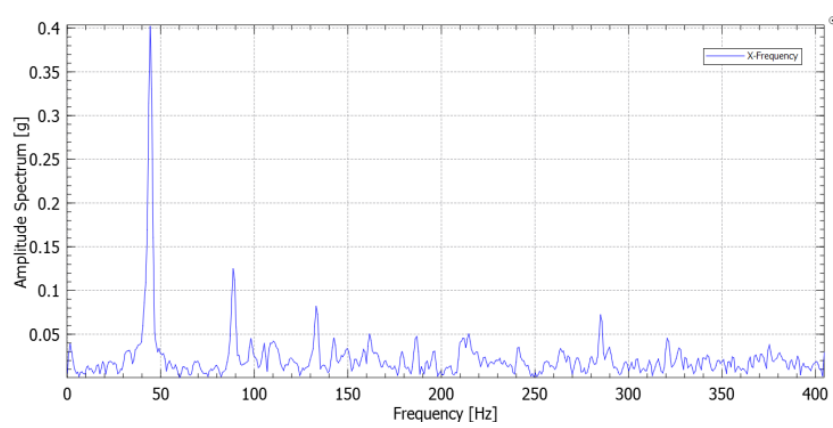

Figure 9 Vibration spectrum at the motor drive end(MDE) (Radial-vertical Direction) after attaching DVA.

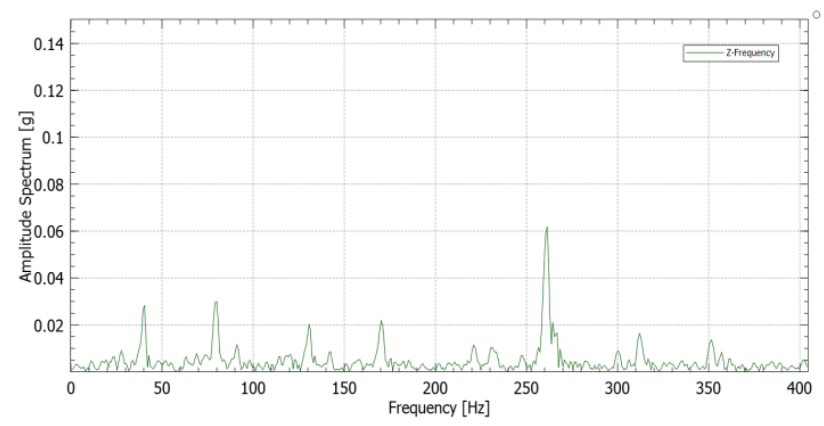

Figure 10: Vibration spectrum at the MDE (Radial-H Direction) before attaching DVA.

Comparing Figure. 2 with Figure. 9 the vibration spectrum up to 0.4 amplitude is available at the motor drive end for the radial vertical direction. Looking at the spectrum we can easily say that subsequent $1 \mathrm{X}, 2 \mathrm{X}$ amplitudes have been reduced because of attachment of DVA. For the radial Horizontal direction available in Figure. 3 as well as Figure.10 the vibration 
spectrum up to 0.14 amplitude the amplitude values change for the $1 \mathrm{X}, 2 \mathrm{X}$, and subsequent frequency multipliers.

According to ISO 10816-3 we need velocity root mean square values for diagnosing the health of the rotating machines. By using an FFT analyzer Vrms readings in $\mathrm{mm} / \mathrm{s}$ have been recorded both at the motor drive end as well as at the non-drive end.

Table 1 Vibration readings comparison before and after attaching DVA.

\begin{tabular}{llccc}
\hline $\begin{array}{l}\text { Measuring } \\
\text { point }\end{array}$ & Direction & $\begin{array}{c}\text { Before DVA } \\
\text { Vrms }\end{array}$ & $\begin{array}{c}\text { After DVA } \\
\text { Vrms }\end{array}$ & $\begin{array}{c}\text { Reduction } \\
\text { (in \%) }\end{array}$ \\
\hline \multirow{2}{*}{ Horizontal } & 10.18 & 9.00 & $11.59 \%$ \\
& Axial & 10.39 & 0.70 & $93.26 \%$ \\
& Vertical & 4.03 & 0.42 & $89.57 \%$ \\
& Horizontal & 4.53 & 1.34 & $70.41 \%$ \\
Axial & 8.98 & 3.04 & $66.14 \%$ \\
& Vertical & 4.24 & 3.32 & $21.69 \%$
\end{tabular}

\section{DISCUSSION}

From the FFT response Figure. 2 to Figure.7 we can see that the peaks are mostly at 1X RPM in a vertical and horizontal direction. As per the condition monitoring basics, the presence of rotating unbalance is justified. After attaching the DVA with rubber as damping material we can see the reduction of the Amplitude Spectrum peaks at $1 \mathrm{X} \mathrm{rpm}$. Apart from the radial unbalance axial vibration disturbance is also gets reduced. In the DVA design, $1 \mathrm{~mm}$ axial clearance is there between the outer hub and the inner bearing. This has taken care of a reduction in the axial vibrations.

\section{CONCLUSION}

As per ISO 10816-3 below $15 \mathrm{KW}$ external driver rigid support rotating systems the measured Vrms value should be less than $4.5 \mathrm{~mm} / \mathrm{s}$ for unlimited long term operation allowable condition. Looking at Table $\mathrm{I}$ it is concluded that before attaching DVA all the Vrms readings are almost above $4 \mathrm{~mm} / \mathrm{s}$ at the motor drive end and motor non-drive end. By observing DVA performance it is found that the vibration level has been reduced around Radial- Horizontal 51.38\%, Axially 63.69\%, and Radial-vertically 55.72\%. 


\section{REFERENCES}

Watts, P.1883. On a method of reducing the rolling of ship at sea. Transactions of the Institute of Naval Architects. 24:165-190.

Frahm, H. 1909. Device for damping vibrations of bodies. U.S. Patent No. 989958.

Ormond Royd, J. \& Den Hartog, J.P. 1928. Theory of the dynamic vibration absorber. Transactions of the American Society of Mechanical Engineers.50:9-22.

Brock, J. E. 1946. A note on the damped vibration absorber. Journal of Applied Mechanics.68. A-284.

Warburton, G.B.1981.Optimum absorber parameters for minimizing vibration response. Earthquake Engineering and Structural Dynamics. 9.

Ioi, T.\& Ikeda, K. 1978. On the dynamic vibration damped absorber of the vibration system. Bulletin of the Japanese Society of Mechanical Engineering. 21(151): 64-71.

Randall, S.E.; Halsted, D.M \& Taylor, D.L.1981. Optimum Vibration Absorbers for linear damped system. J.Of Mechanical Design. ASME.103(4) : 908-913.

Tasi, H.C. \& Lin, G.C.1993. Optimum Tuned Mass Dampers for minimizing steady-state response of support excited and damped systems. Earthquake Engg. And structural dynamics. 22(11): 957-973.

Tasi, H.C. \& Lin, G.C. 1994. Explicit formulae for optimum absorber parameters for force excited and viscously damped system. J. Of Sound and Vibration. 176(5): 585-596.

Rana, R. \& Soong, T.T.1998. Parametric study and simplified design of tuned mass dampers. Engineering Structures, 20(3): 193-204.

Asami,T., Osamu, N. \& Amr, M.B.2002. Analytical Solutions to $\mathrm{H} \infty$ and $\mathrm{H} 2$ Optimization of Dynamic Vibration Absorbers Attached to Damped Linear Systems. Vibration Acoustics ASME.

Cheung,Y.L.\& Wong,W.O.2002. H2 optimization of a non-traditional dynamic vibration absorber for vibration control of structures under random force excitation. Journal of Sound and Vibration.

Kefu, L. \& Jie, L. 2005. The damped dynamic vibration absorbers: revisited and new result. Journal of Sound and Vibration. 284:1181-1189.

Bakrez, S.V. \& Jangid, R.S. 2007. Optimum parameters of tuned mass damper for damped main system. Structural Control and Health Monitoring. Wiley Intercedence.

Argentini, T.2015. A Closed-Form Optimal Tuning of Mass Dampers for One Degree-ofFreedom Systems Under Rotating Unbalance Forcing. Journal of Vibration and Acoustics.ASME. 
Sheth, A.J. \& Patel, U.A.2020. Determination of Exact Optimal Tuning of Dynamic Vibration Absorbers to Control Vibration due to Rotating Mass Unbalance. First International Conference on Future Technologies in Manufacturing, Automation, Design \& Energy. NIT Pondicherry.

Tienhaara, H. \& Heikki, M. 2008. Reduction of vibration levels on the ABB TPL turbocharger using the tuned mass damper for Wartsila 9L46 engine.Engine dynamics and vibration control.

Taplak, H. 2012. Passive balancing of a rotating mechanical system using GA. Scientia Iranica.

Hao,K.Y. 2011.Tuned Vibration Absorber for suppression of hand-arm vibration in electric grass trimmer. International Journal of Industrial Ergonomics.

Huang, S.C. \& Lin, K.A.2014. A New Design of Vibration Absorber for Periodic Excitation. Shock and Vibration.

Abdullah, 0.2015. Design and Experimental Implementation of a Beam-Type Twin Dynamic Vibration Absorber for a Cantilevered Flexible Structure Carrying an Unbalanced Rotor: Numerical and Experimental Observations. Hindawi Publishing Corporation. Shock and Vibration. Article ID 154892.

Aida, A. \& Daman, A. 2016. The Influence of Dynamic Vibration Absorber to Reduce the Vibration of Main System with 2-DoF. American Institute of Physics.

Ghodge, V. 2018. Design and Validation of a Mass Tuned Dynamic Vibration Absorber. International Journal of Advance Research. Ideas and Innovations in Technology.

ISO 1940-1 Second edition 2003-08-15 Mechanical vibration. Balance quality requirements for rotors in a constant state Part 1: Specification and verification of balance tolerances.

Sutar, S.; Warudkar, V. \& Sukathankar, R. 2018. Vibration Analysis of Rotating Machines with Case Studies. International Journal of Scientific \& Technology Research. 7.

Awrejcewicz, J. \& Puzyrov, V. 2017. On The Optimum Absorber Parameters: Revising the Classical Results. Journal Of Theoretical and Applied Mechanics.:1081-1089.

Nguyen, D.; Khang, V.; Nguyen, T. V. \& Vu Duc, Phuc.2018. A Procedure for Optimal Design Of A Dynamic Vibration Absorber Installed in The Damped Primary System Based On Taguchi's Method. Vietnam Journal of Science and Technology. 56 (5): 649-66. 
Shaoyi,Z.; Claire, J.M. \& Chesne, S. 2019.Closed-form solutions to optimal parameters of dynamic vibration absorbers with negative stiffness under harmonic and transient excitation. International Journal of Mechanical Sciences. Elsevier.

Lijesh, K.P. \& Hirani, H. 2014. Stiffness and damping coefficients for rubber mounted hybrid bearing. Lubrication Science. 26(5).

Li, J.C.; Zhang,H.S.; Zhao,X. Y.; Jiang, J.G.; Wu,Y.X.; Lu1, Y.L.; Zhang, L. Q. \& Nishi, T. 2019. Development of high damping natural rubber/butyl rubber composites compatibilized by isobutylene-isoprene block copolymer for isolation bearing. Express Polymer Letters. 13(8).: 686-696.

Christoforou, A.P. \& Yigit, A.S. 2016. Inelastic impact and the coefficient of restitution. Journal of Engineering Research. 4(4).

Falah, A. H.\& Khorshid, E.A. 2014. Optimum modeling of a flexible multi-bearing rotor system. Journal of Engineering Research. 2(2):1-27.

Alaskari, A.M. \& Oraby, S.E.2018. Adaptive control simulation to optimize metal removal for rough turning. Journal of Engineering Research. 6(2): 209-231.

Wonjoon, K.; Donggun, P.; Yong, M. K.; Taebeum, R. \& Myung, H. Y. 2018. Sound quality evaluation for vehicle door opening sound using psychoacoustic parameters. Journal of Engineering Research. 6(2).

Alhazza, K.A. \& Masoud, Z.N.2013.A Novel Wave-Form Command Shaper for Overhead Cranes. Journal of Engineering Research. 1(3):181-209. 